\title{
Research on the Dispirited Culture-Based on The BoJack Horseman
}

\author{
Feilin Chen $^{1}$
}

\author{
Guangdong Experimental High School, AP International Program, Guangzhou, Guangdong 510378, China \\ *Corresponding author. Email: angela@cas-harbour.org
}

\begin{abstract}
This study aims to interpret the relationship between the BoJack Horseman and dispirited culture, and analyze the psychological ecology of contemporary young people reflected behind. Dispirited culture, a new form of youth subculture, often refers to the language, words, and images with negative emotions. This study studies many related fields of literature and links them to make a summary. According to the conclusion, the character shaping, plot development, and scene details in the animation all reflects some of the components of the funeral culture. This study analyzes the case where this animation helped to drive the dispirited culture and provides a reference for subsequent research.
\end{abstract}

Keywords: The BoJack Horseman, Dispirited culture, Popular culture, Mass media, Network subculture

\section{INTRODUCTION}

Roughly in 2016, the animation the BoJack Horseman became popular along with a concept called dispirited culture. Relying on the communication characteristics of the Internet media and the cultural characteristics of youth groups, it has further spread to the real world, which has greatly reflected the ecology of youth subcultures, become a cultural phenomenon, and attracted the attention of the whole society. During the process that the dispirited culture spread, the influence of Western new century literary and artistic works represented by cartoons such as the BoJack Horseman cannot be underestimated. The many screen-shots from the BoJack Horseman became widespread on various social media. The BoJack Horseman became so popular suddenly and quickly that it caused a doubt: how exactly does this animation shows dispirited culture and become popular among the youths? This study aims to answer this question and analyze the psychological ecology of contemporary young people reflected behind.

\section{THE DEFINITION AND ORIGIN OF DISPIRITED CULTURE}

The academic community has not yet clearly defined the "dispirited culture", but in combination with its prominent features, the concept of "dispirited culture" can be defined as: the decadent, hopeless, and pessimistic popular among the young emotions and colors such as language, writing or painting. It is a new form of youth subculture. Though the word "dispirited culture" is a Chinese saying, the phenomenon it refers to has spread worldwide. To a certain extent, the "dispirited" style of dispirited culture is precisely derived from the collage, through the misappropriation and tampering of the inspiring paragraphs and memes that have been circulated in the previous cyberspace, so that they are reordered or expressed. The rewriting of meaning on the basis of the environment update completely reversed the meaning of the original paragraph, or completely subverted the context of the original picture, and the negative energy attached to the new meaning after the reversal spread in the network space[2]. The lines and scenes of the BoJack horseman itself are already full of negative meaning, therefore the screen-shots can be easily taken and posted, omitting the steps of secondary creation, which contributes to the widespread of this animation.

It may not be possible to trace the origin of this cultural phenomenon precisely. But it can be traced to the questioning of these during the 2000s: 9-11, the Iraq War, the anti-imperialist governments in Latin America and the 2007/2008 economic crisis seemed to overrule any notion of an "end of history". That major conflicts had ended after the triumph of capitalism over state socialism could hardly be believed in the face of so many areas of confrontation. Furthermore, some rebellion against the characteristic traces of techno-optimism and de-mobilisation proper of mainstream culture could be found within mainstream films: Fight Club (director David Fincher, 1999) and V for Vendetta (director James McTeigue, 2005) have been instrumentalised in recent years by anti-globalisation movements and forces from quite different political traditions. In some cultural traditions, there are also some characteristics seemed to have something to do with the dispirited culture. Poetry culture is an important part of Chinese culture. Many well-known poets and famous poets have also been frustrated, failed, and downcast. A large number of famous poems were written to record or express the frustration of these poets, which was similar to the languages, words, or pictures that are popular now among youth with emotions of decadence, despair, and pessimism. 


\section{SEVERAL FEATURES IN THE BOJACK HORSEMAN THAT CONVEY THE SIGNAL OF DISPIRITED CULTURE}

\subsection{The Plots Associated With Reality}

The animation reflects the anxiety of contemporary young people about life and society by narrating a series of events around the protagonist. The protagonist of the BoJack Horseman is a horse, which is an overdone, wealthy but depressed Hollywood star. He always makes commitments but never fulfill them. He is self-deprecating all the time but never thinks about making progress. His words are mean, never thinks about other people's felling, and even breaks up with his girlfriend without any apology. Though this character looks awful, but it certainly let many young people see their own projection on him more or less. The story revolves around his daily life, and many social phenomena are satired during the development of the plot, such as star hype, judicial injustice, and the media deceiving the public. These plots may also reflect some reasons that why young people are so dispirited now: as the social media become more and more advanced, many dark facts that are usually deeply hidden in the corners of society are constantly exposed. These incidents are usually very bad, and knowing too much about them can have an impact on the ideology of some young people with less mentality. According to a concept called negative effect in psychology, when we form an overall impression of something, negative information may play a greater role. That is, when the other conditions are equal, a negative trait has a greater impact on the impression than a positive trait. What's more, young people's lives are under serious stress now. In China, increasing house prices put many young people in a state of extreme anxiety. Similarly, in Japan, a persistently slumping economy has almost made young people give the idea of struggle. Many young people no longer believe in old teachings, sayings that people should struggle for happiness, which they are taught by elder. Instead, many mean and harsh lines in the BoJack Horseman are shared by them everyday on social media. It is undeniable that part of this behavior is that young people are pursuing trends, but it is more because those lines resonate with them express their dissatisfaction with the real society.

\subsection{Artistic Style of Details}

In this animation, some hidden details are also worth investigating, like the paintings imitating famous paintings. The target these paintings imitate are carefully selected. Almost all of them are representative paintings in certain artistic styles such as Pop Art. BoJack is a fan of Pop Art. In the animation, the paintings of horseshoes hanging on the wall of BoJack's bedroom imitated Marilyn Monroe, the representative painting of Andy Warhol, 1928-1987. Andy Warhol is an advocate and leader of Pop Art and an artist with the greatest influence on Pop Art. As early as Bojack became famous in his representative sitcom, his background wall was already full of paintings of Keith Haring (1958-1990), whose work has a strong Pop Art style. American Pop Art inherited the spirit of Dada in the pursuit of art, so it also has the title of New Dada. The main characteristics of Dada include: the pursuit of sober irrational state, refusal to agree on the standard of art, disillusionment, cynicism, the pursuit of unintentional, accidental and casual state, and so on. Dadaists believe that "Dada" is not an art, but an "anti-art". No matter what the current artistic standards are, Dadaism goes against it. Likewise, dispirited culture is also a claim anti the traditional concept that young people should be motivated and work hard. The word "dispirited" is mainly reflected in the negative, decadent, insensitivity and indifferent progress of the discourse, which is in sharp contrast with the cheerful, upward, and aggressive. dispirited culture with decadent, negative and other negative energy as the core feature is also clearly contrary to the orthodox mainstream culture, directly subverting the values advocated by the mainstream culture, and even positively challenging the mainstream culture to young people's energetic, positive and other images. The authority of designing and developing expectations is a typical other contradicting mainstream culture[2].

\subsection{The Nature of Animal Narrative}

Another feature is that the nature of animal narrative in the animation is a parody of artistic symbols, which constructs a world full of metaphors. The protagonist of the animation is a horse. Bred for work, transportation, and finally racing, horses are becoming superfluous in contemporary society, since there are fewer demands for them in the much-changed industries of transportation, agriculture, and sport. Names like Secretariat, the iconic racehorse who won the Triple Crown in 1973 and who plays a significant role in the show, are phenomena of the past[3]. Relatively, BoJack used to be a famous comedy actor, starring in a very famous situation comedy called Horsin' Around. Just at the beginning of the story, BoJack had been lain around all day for 18 years after the comedy's cancellation. His whole life, he has aspired to be like Secretariat, or, at the very least, to play his role in a movie[3]. This metaphor not only introduces the background information of the BoJack Horseman, but also predicts the future development of the story: this decadent horse still indulged to deprave himself, continuing his boring daily life full of black humor.

\subsection{The Equalization of Animals and Human Beings}

Except for the metaphors, the fact that animals in the cartoon act like human beings is also meaningful. Characters in this cartoon are mixed with animals and human beings. Animals talk, work, and live like humans, 
but they still retain some of their species identity. There is another potential sign of the dispirited culture, which is that derogation from people has become a fairly normal cultural trend. In the language of young people, some animal words have spoken words that are quite positive and very spoiled, which is also a noteworthy phenomenon. The progress of human civilization is constantly fading the animal nature of the body, decorating itself with culture, and separating people from animals. Any alienation from people means that their value is in a negated state, especially when they are made into an animal. It can be boldly speculated that this animation expresses a dispirited core: Every creature living in the world are no different from each other. The natural ecological division between human beings and animals is broken, which means human beings will also be dominated by instincts for easy enjoyment or be replaced by higher-level creatures that may appear in the biological chain. Under this idea, new questions come: what's the meaning of life? Is the action pursuing life's meaning meaningful? Hearing about the death of Sarah Lynn, BoJack's pursuit of the meaning of life suffer a blow. As a result, the metaphor level of the play has also been extended to the cultural level[4]. The main ideas of dispirited culture also includes the negation of life, claiming that life is meaningless.

\subsection{Contended With Violence}

Violent content in this animation reflects a part of cause of the formation of the dispirited culture. According to statistics, there are 36 violent scenes in the 12 episodes of the first season of the drama, with an average of 3 episodes per episode. Based on the episode length of 25 minutes, the violent scene appears every 8 minutes. Except for episode 4 , violent scenes appeared in all episodes. A maximum of 5 violent scenes in an episode. Statistics on the punishment of the perpetrators of violence show that the vast majority of perpetrators of violence $(97.2 \%)$ in the play have not received any punishment and no reward. However, the characters in the play don't care about the injured person's attitude. In up to half of the cases, the attitude towards the injured person is not expressed. In the case of performance, most of the attitudes towards the injured are indifferent and disregarded. This indifference is often caused by the idea that people do not want to be involved in the incident and only want to protect themselves. The most common causes of violence are "temporary venting" (30.5\%) and "no special reason" (27.8\%), which together account for more than $50 \%$ of all violence. At the same time, unreasonable and unjust violence accounted for $44.4 \%$ of the violence scenes in the play[6]. This reflects the irritable and changeable character of the actor in the play and the random and unreasonable characteristics of the violent content of the play. A setting of social environment that is full of unreasonability and indifference is constructed in the animation. This is actually a reflection of real social environment in which dispirited culture originates, indicating that young people living in this social environment are full of anxiety and insecurity. The youth dispirited culture is the inner cry and self-deprecating behavior of the contemporary youth facing the great pressure of survival and development, but wanting to do something but being helpless. It is a way for young people to vent their emotions and relieve stress, as well as a gentle attitude against reality[7].

\section{THE POSITIVE MEANING CONTAINED IN THE DISPIRITED CULTURE}

But does the BoJack horseman reflect just only the negative side of dispirited culture? This animation not only develops its plot around BoJack but also his friends. His human partner, Todd, lives in his home and is an asexual; his manager and ex-girlfriend Caroline is a workaholic and longs for a child came to save her life; the female human who wrote an autobiography for BoJack, Dian, was clever, talented, and thoughtful, but she also had the same decadent as BoJack[5]. In the end, Todd met his proper partner, Caroline adopted a child and arranged her career and family well, and Dian married a person who can warm her. These characters all got their own happy end with struggle and effort. The screenwriter shows the difficulties and frustrations encountered in life, personal shaking and crisis to the audience. People can see their own projection in it, seeing their own life dilemma and the struggle to change. The play expresses the uniqueness of the person through the characterization of the character and the narrative of the story, and uses this to tell the audience that life is often unsatisfactory, encountering setbacks, or even simply unhappy, this will happen in every personally. People should not escape and face it. The play also uses this expression of values to complete the transition from a depressed play to a inspiring play[5].What's more, active self mocking, which may be manifested in saying discouraged words or posing discouraged contents on the internet, actually helps people relieve their pressure. In the end of most episodes of the animation, good things usually occurred. It is not the fairy-tale great consummation, but some obscure details that let people appreciate and feel encouraged. Audiences can easily substitute themselves into the plot, therefore get inspired for re-own the hope of future. This is telling the idea that though the life is considered meaningless and always unsatisfactory, but if the struggle for life is keeping, there will certainly be a turning point in life.

\section{CONCLUSION}

In conclusion, dispirited culture is a very novel youth subculture that generally represents the decadent, hopeless, and pessimistic popular among the young emotions and colors such as language, writing or painting. It can be traced to the questioning of some negative historical events In the BoJack Horseman, the anxiety of contemporary young people about life and society, a part of dispirited 
culture, is narrated by the developing of a series of events around the protagonist. The Artistic style of details, the nature of animal narrative, the equalization of animals and human beings, and the violent content all express some part of the dispirited culture. Although the BoJack Horseman reflects the negative side, it still contains some positive features of dispirited culture. It tells the idea that though the life is considered meaningless and always unsatisfactory, if the struggle for life is keeping, there will certainly be a turning point in life. This study analyzes and summarize the connection between this animation and the dispirited culture, which provides a reference for the subsequent research. There is also something else can be written about several specific characters' storyline and how to correctly guide contemporary young people to amplify the positive side of dispirited culture. But since this study mainly aims to find out the relationship between the whole animation and the dispirited culture, such content is not analyzed in detail.

\section{ACKNOWLEDGMENT}

During the writing of this article, I received careful guidance from the instructor. From the selection of topics, the guidance of ideas, the organization of the text, and the arrangement of the structure, the instructors have devoted a lot of effort. Here I sincerely thank the instructor for guidance and care in my studies.

\section{REFERENCES}

[1] Xiao, Z. Y., Chang, J. F., Sun, J. (2017) From "Fei Chai" to "Ge You Lie": A Study of Dispirited Culture of Internet Youth from the Perspective of Social Psychology. Youth and Adolescent Studies. (2017(03))3-7+31.

[2] Dong, K. Y. (2017) Phenomenon of Dispirited culture and Youth Social Mentality Perspective. China Youth Study. (2017(11))23-28.

[3] Sánchez Saura, R. (2019) Bojack Horseman, or the exhaustion of postmodernism and the envisioning of a creative way out. Creativity Studies, 12(2), 291-300.

[4] Xu, K. (2019) Urban Animal Farm: the M etaphors in BoJack Horseman. Contemporary Cinema. 2019(04):174-176.

[5] Dong, J. (2019) An Interpretation of the Postmodernity of the American Drama

[6] The BoJack Horseman. Research on Transmission Competence. 2019, 3(11):14-15.
[7] Wang, X. Q. (2018) An Analysis of Violent Contents in the Animated Drama the BoJack Horseman. Media Forum. 1(03):114-115.

[8] Zhao, B.Y. (2019) Typical Characteristics, Reasons and Guiding Paths of Contemporary Youth's Dispirited Culture. Beijing Youth Research 28(04):33-37 